\title{
Exploitation of novel wild type solventogenic strains for butanol production
}

\author{
Fengxue Xin ${ }^{1,2}$, Wei Yan ${ }^{1}$, Jie Zhou ${ }^{1,2}$, Hao Wu ${ }^{1,2}$, Weiliang Dong ${ }^{1,2}$, Jiangfeng Ma ${ }^{1,2}$, Wenming Zhang ${ }^{1,2}$ \\ and Min Jiang ${ }^{1,2^{*}}$
}

\begin{abstract}
Butanol has been regarded as an important bulk chemical and advanced biofuel; however, large scaling butanol production by solventogenic Clostridium sp. is still not economically feasible due to the high cost of substrates, low butanol titer and yield caused by the toxicity of butanol and formation of by-products. Renewed interests in biobutanol as biofuel and rapid development in genetic tools have spurred technological advances to strain modifications. Comprehensive reviews regarding these aspects have been reported elsewhere in detail. Meanwhile, more wild type butanol producers with unique properties were also isolated and characterized. However, few reviews addressed these discoveries of novel wild type solventogenic Clostridium sp. strains. Accordingly, this review aims to comprehensively summarize the most recent advances on wild type butanol producers in terms of fermentation patterns, substrate utilization et al. Future perspectives using these native ones as chassis for genetic modification were also discussed.
\end{abstract}

Keywords: Solventogenic Clostridium sp., Fermentation pattern, Substrate utilization, Novel genus

\section{Background}

Biobutanol has gained great attention as a liquid transportation fuel owning to its similar physical and chemical properties to gasoline in addition to being renewable $[1,2]$. Its higher energy content, lower affinity to water, better blending capacities and compatibility with current car engineering make butanol more desirable than ethanol. Biobutanol production through traditional acetonebutanol-ethanol (ABE) fermentation using solventogenic Clostridium sp. strains is an industrially established process, and large scaling biobutanol production has been applied for more than 100 years [3-5]. However, it is still not economically feasible due to several obstacles, such as the high cost of traditional feedstocks (starchy based materials), low butanol titer caused by the lipophilic property of butanol and low butanol yield caused by the formation of side products, mainly acetone [6-8].

\footnotetext{
*Correspondence: bioengine@njtech.edu.cn

1 State Key Laboratory of Materials-Oriented Chemical Engineering,

College of Biotechnology and Pharmaceutical Engineering, Nanjing Tech University, Puzhu South Road 30\#, Nanjing 211816, People's Republic of China

Full list of author information is available at the end of the article
}

In nature, solventogenic clostridia, such as $C$. acetobutylicum, C. beijerinckii and C. pasteurianum are several microorganisms able to ferment monosaccharides, including hexose (e.g., glucose) and pentose (e.g., xylose) to butanol, which typically produce butanol, acetone, and ethanol with a mass ratio of 6:3:1 [6]. However, solventogenic clostridia can not directly utilize polysaccharides, such as cellulose and hemicellulose and other organic wastes, such as glycerol [9]. C. acetobutylicum ATCC 824 and C. beijerinckii NCIMB 8052 are two most wellknown butanol-producing species. Genetic modification of these strains has been comprehensively investigated to improve their fermentation efficiencies, including the improvement of butanol tolerance, simultaneous utilization of glucose and xylose, elimination of acetone production and conversion of acetone into isopropanol [10-13]. However, it should be noticed that due to the complex of $\mathrm{ABE}$ fermentation pathway, metabolic re-construction of central metabolic pathway would cause some undesired behaviors. For instance, the disruption of acetoacetate decarboxylase gene $(a d c)$ in $C$. acetobutylicum could minimize the acetone formation; however, butanol production of the recombinant strain was also affected 
significantly. Only through the supplementation of costly artificial electron carriers and buffering agency, butanol production was recovered, which makes the butanol production process less economically feasible [13].

Solventogenic clostridia are both spore forming and obligate anaerobes, which have relatively simple growth requirements, and various isolation methods have been well documented [14]. These bacteria have been found to be most commonly associated with living plant materials rather than decaying plant materials or soils. The most recent advances on improvement of butanol production through strain genetic modification and separation technologies have been reviewed in detail elsewhere [2-4, 6]. However, few reviews regarding butanol production using wild type solventogenic strains were reported. As known, native microbes with unique properties such as indigenous elimination of acetone formation could be good chassis for further genetic modification $[15,16]$. Hence, in this review, we specifically focused on current advances on butanol production using novel wild type solventogenic Clostridium sp. Further perspectives regarding these native butanol producers were also discussed.

\section{Solventogenic Clostridium sp. with untraditional butanol fermentation pattern}

In $\mathrm{ABE}$ fermentation process, acetone generally accounts for $30 \%$ of total solvent mass, which will lower the butanol yield. In addition, acetone does not qualify as fuel and should be separated from the final products, which will further increase the following separation cost $[3,17]$. Aiming to solve this obstacle, series of work have been carried out to eliminate the acetone formation through genetic modification. The most direct method is to knock out genes related with acetone production. Indeed, the minimization or suppression of acetone production through interruption of acetone synthetic pathway in vivo led to less acetone production; however, butanol production was also significantly affected with the accumulation of more volatile fatty acids (VFAs), mainly acetate and butyrate rather than solvents [18]. For example, the disruption of acetoacetate decarboxylase gene $(a d c)$ in $C$. acetobutylicum reduced acetone production to negligible levels with only $0.21 \mathrm{~g} / \mathrm{L}$; however, only $7.41 \mathrm{~g} / \mathrm{L}$ of butanol production occurred, which is much lower than that of parent strain $(13.62 \mathrm{~g} / \mathrm{L})$. The final butanol titer could only reach the similar level through the metabolic regulation of electron flows with the supplementation of artificial electron carriers, methyl viologen. These artificial electron carriers could alter the carbon flux towards solvents rather than VFAs formation, and butanol production capability could then be recovered [19]. However, this will make the recombinant strain less competitive due to the raised cost caused by the supplementation of expensive electron carriers. On the contrary, indigenous acetone-uncoupled solventogenic Clostridium sp. shows promising alternative for butanol production. For instance, Gong et al. found that native C. tetanomorphum strain DSM665 could re-assimilate butyrate and acetate for butanol-ethanol $(\mathrm{BE})$ production with the indigenous elimination of acetone. After the process optimization, strain DSM665 could produce $9.81 \mathrm{~g} / \mathrm{L}$ of butanol and $1.01 \mathrm{~g} / \mathrm{L}$ of ethanol. Further enzymatic analysis indicated that the activity of acetate/butyrate: acetoacetyl-CoA transferase responsible for acetone production was not detected in C. tetanomorphum strain DSM665 [20]. The genome sequence analysis showed that no genes of $c t f A / B$ and $a d c$ exist, which are typically parts of an acetone synthesis pathway in C. tetanomorphum. Taken together, compared to the strategy of acetone elimination by metabolic engineering, adoption of native acetone uncoupled solventogenic Clostridium strains will not affect butanol production, which could be used as the robust chassis to further improve the butanol titer.

Alternatively, further conversion of acetone into more value-added product, such as isopropanol, offers another promising method [21]. In addition to the introduction of isopropanol synthesizing genes into solventogenic Clostridium sp., some native solventogenic Clostridium sp. also show the capability of direct isopropanol production. C. beijerinckii NRRL B-593 was the first identified one to produce isopropanol-butanol-ethanol (IBE) through the indigenous expression of s-alcohol dehydrogenase $(s-A D H)$, which has been comprehensively adopted as the genetic tool for conversion of acetone into isopropanol by other solventogenic Clostridium sp., such as C. acetobutylicum [22]. However, isopropanol production levels are not conclusive based on different studies. Until now, more isopropanol producing organisms have been isolated and characterized. For instance, $\mathrm{Ng}$ et al. [23] isolated Clostridium sp. BT10-6, M10-1 and PU31-4 from the nature reserve soil. Especially, strain BT10-6 could accumulate up to $5.26 \mathrm{~g} / \mathrm{L}$ of isopropanol after $48 \mathrm{~h}$ with isopropanol productivity of $0.13 \mathrm{~g} / \mathrm{L} / \mathrm{h}$, which is 4.6 times of $0.029 \mathrm{~g} / \mathrm{L} / \mathrm{h}$ given by C. beijerinckii NRRL B593. Meanwhile, BT10-6 could produce a slightly lower butanol titer and higher butanol productivity compared to C. beijerinckii NCIMB 8052. However, the detailed mechanism was not addressed. More recently, Xin et al. [24] isolated another native isopropanol-butanol (IB) producer, Clostridium sp. strain NJP7, which also shows efficient solvent production from polysaccharides, such as hemicellulose through consolidated bioprocessing (CBP). With the enhancement of buffering capacity and alcohol dehydrogenase activities through the supplementation of NADPH precursor-nicotinamide, butanol 
and isopropanol titer by Clostridium sp. strain NJP7 was finally improved to $12.21 \mathrm{~g} / \mathrm{L}$ and $1.92 \mathrm{~g} / \mathrm{L}$, respectively. Solvent productivity could also be enhanced to $0.44 \mathrm{~g} / \mathrm{L} / \mathrm{h}$. Furthermore, with in situ extraction using biodiesel, the amount of butanol and isopropanol was finally improved to $25.58 \mathrm{~g} / \mathrm{L}$ and $5.25 \mathrm{~g} / \mathrm{L}$ in the fed batch mode. Meanwhile, some other native IB producers were also discovered, such as Clostridium sp. strain A1424, whose $16 \mathrm{~S}$ rRNA sequence shows $99.92 \%$ similarity to $C$. diolis DSM 5431. Strain A1424 could produce $9.43 \mathrm{~g} / \mathrm{L}$ of butanol and $4.49 \mathrm{~g} / \mathrm{L}$ of isopropanol at $\mathrm{pH} 5.5$ with the consumption of $46.35 \mathrm{~g} / \mathrm{L}$ of glucose, respectively, which are the highest values in glucose-based batch fermentations using natural IB producers [11]. It is known that sADH is generally NADPH dependent; hence, NADPH regulation with the supplementation of various electron carriers could be an efficient way for further improvement of isopropanol production [25] (Fig. 1).

\section{Solventogenic Clostridium sp. with expanded spectra of substrate utilization}

Solventogenic Clostridium sp. with capability of simultaneous utilization of glucose and xylose in lignocellulosic hydrolysate

The efficient and simultaneous conversion of both pentose and hexose is a significant hurdle to the economic utilization of ligno-biomass hydrolysates for the second biofuel generation [26, 27]. Scientists noted "the lack of a microorganism able to efficiently ferment all sugars released by the hydrolysis from lignocellulosic materials has been one of main factors preventing utilization of lignocellulose", because either the desired microorganism is unable to utilize pentose at all (e.g., Saccharomyces cerevisiae) or the organism consumes the sugar mixture sequentially (e.g., first glucose and then xylose) $[6,28]$. Unless both glucose and xylose are utilized, the economic of converting lignocellulosic biomass into bio-based products is unfavorable. Solventogenic clostridia, such as C. acetobutylicum, C. beijerinckii and C. pasteurianum are several organisms able to ferment both pentose and hexose sugars, while high butanol and solvent production and good solvent yields are still obtained from hexose, mainly glucose, whereas significantly lower values are found with pentose, such as xylose [29, 30]. C. acetobutylicum ATCC 824 and C. beijerinckii NCIMB 8052 have shown this inherent xylose metabolism bottleneck. For example, compared to $11.25 \mathrm{~g} / \mathrm{L}$ of butanol production with $100 \%$ utilization of glucose in P2 medium containing $60 \mathrm{~g} / \mathrm{L}$ of glucose by C. acetobutylicum ATCC 824, only $4.23 \mathrm{~g} / \mathrm{L}$ of butanol was produced with the residue of $36.73 \mathrm{~g} / \mathrm{L}$ of xylose under paralleled conditions [30]. When grown in XHP2 medium using $30 \mathrm{~g} / \mathrm{L}$ of xylose

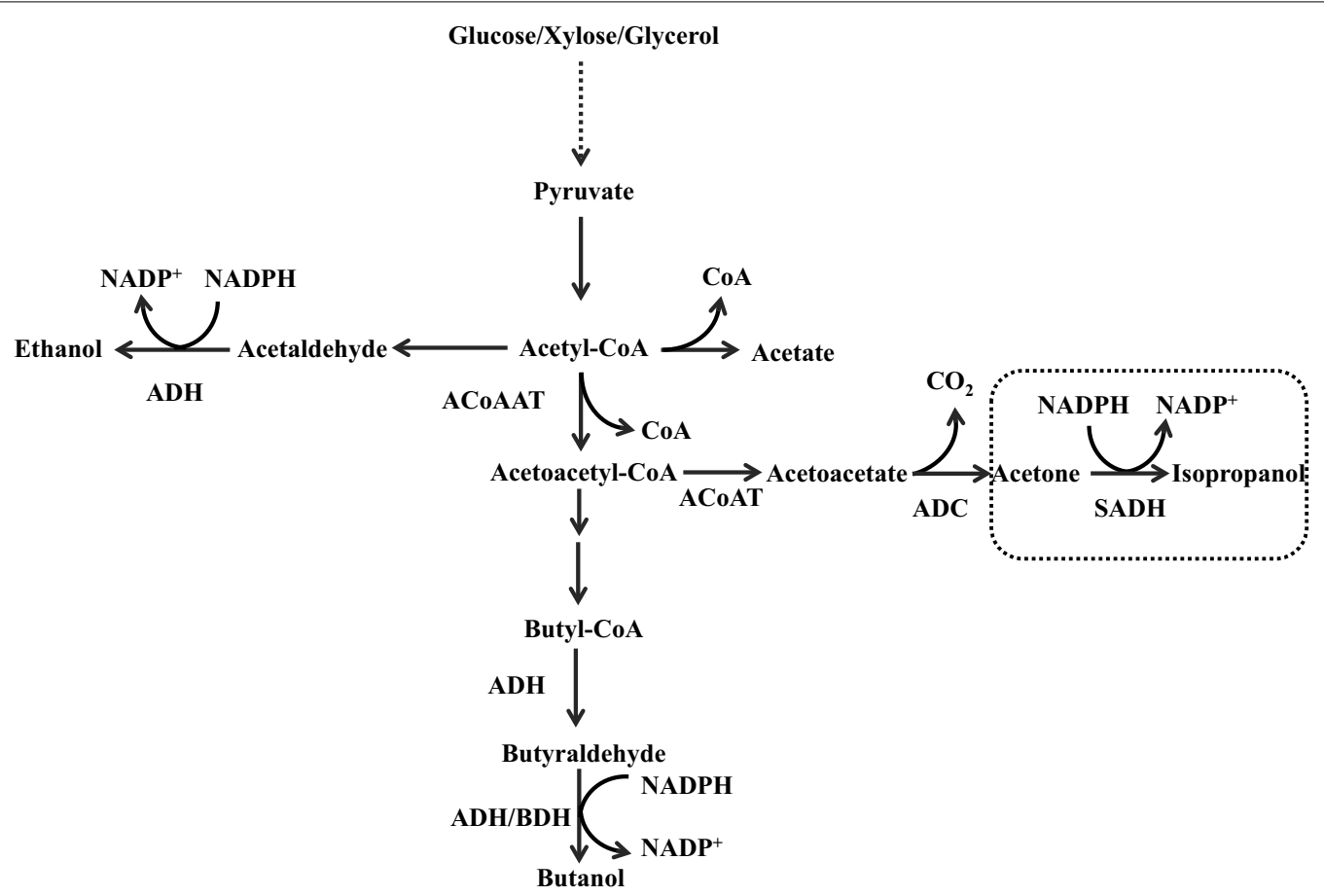

Fig. 1 The metabolic pathway for isopropanol-butanol-ethanol (IBE) production. The box shows the synthetic pathway for isopropanol production from acetone. ACOAAT acetyl-CoA acetyltransferase, ACOAT acetoacetyl-CoA transferase, ADC acetoacetate decarboxylase, SADH secondary alcohol dehydrogenase, $A D H$ alcohol dehydrogenase, $B D H$ butanol dehydrogenase 
as the sole carbon source, C. beijerinckii NCIMB 8052 could only consume $20.20 \mathrm{~g} / \mathrm{L}$ of xylose [31]. The inefficient xylose utilization leads to another big issue that utilization of xylose is severely inhibited when a preferred carbon source, such as glucose exists in the glucose and xylose mixtures [32]. This phenomenon is referred as carbon catabolite repression (CCR), in which microorganisms preferentially utilize a rapidly metabolizable carbon source, along with the inhibition of some genes expression and enzyme activities related to the catabolism of non-preferred carbon resources [33].

A novel solventogenic Clostridium sp. strain $\mathrm{BOH} 3$ has been screened, which showed the highest sugar utilization $(100 \%)$ and butanol production $(14.94 \mathrm{~g} / \mathrm{L})$ capability compared to other reported wild and mutant strains. More importantly, it could produce similar amount of butanol from xylose to glucose [34]. In solventogenic Clostridium species, the non-oxidative pentose phosphate pathway (PPP) is really the only way, by which pentose can be introduced into Embden-Meyerhof-Parnas (EMP) pathway with the final conversion of pyruvate, ATP and NADH $[35,36]$. EMP is the central carbon metabolism for hexose sugars utilization, while PPP (also called hexose monophosphate shunt), which is a major source of pentose phosphates for the supply of C5 and $\mathrm{C} 4$ units for biosynthesis and reducing power, is another branch of hexose metabolism [37]. As indicated by epimerase-transketolase-transaldolase mediating PPP detection and radiotracer studies, equivalent quantities of pyruvate, ATP and NADH are formed per gram of xylose or glucose fermented $[38,39]$. Under the condition of the same amount of sugar utilization, these explain why the products and cell yields of Clostridium sp. strain $\mathrm{BOH} 3$ on glucose and on xylose are nearly identical (Fig. 2).

\section{Efficient metabolism of glycerol to butanol}

In addition to lignocellulosic materials, some other organic wastes are also ideal substrates for biobutanol production, such as waste glycerol. As known, glycerol is a cheaper, simpler and more abundant molecule than glucose, which can be taken up into microbial cells through the facilitated diffusion [40]. Many microorganisms have been reported to possess metabolic pathways that can convert glycerol into different metabolic products, including butanol, 1,3-propanediol et al. However, the most studied solventogenic organisms of $C$. acetobutylicum and C. beijerinckii are unable to grow solely on glycerol, as they cannot re-oxidize the excess

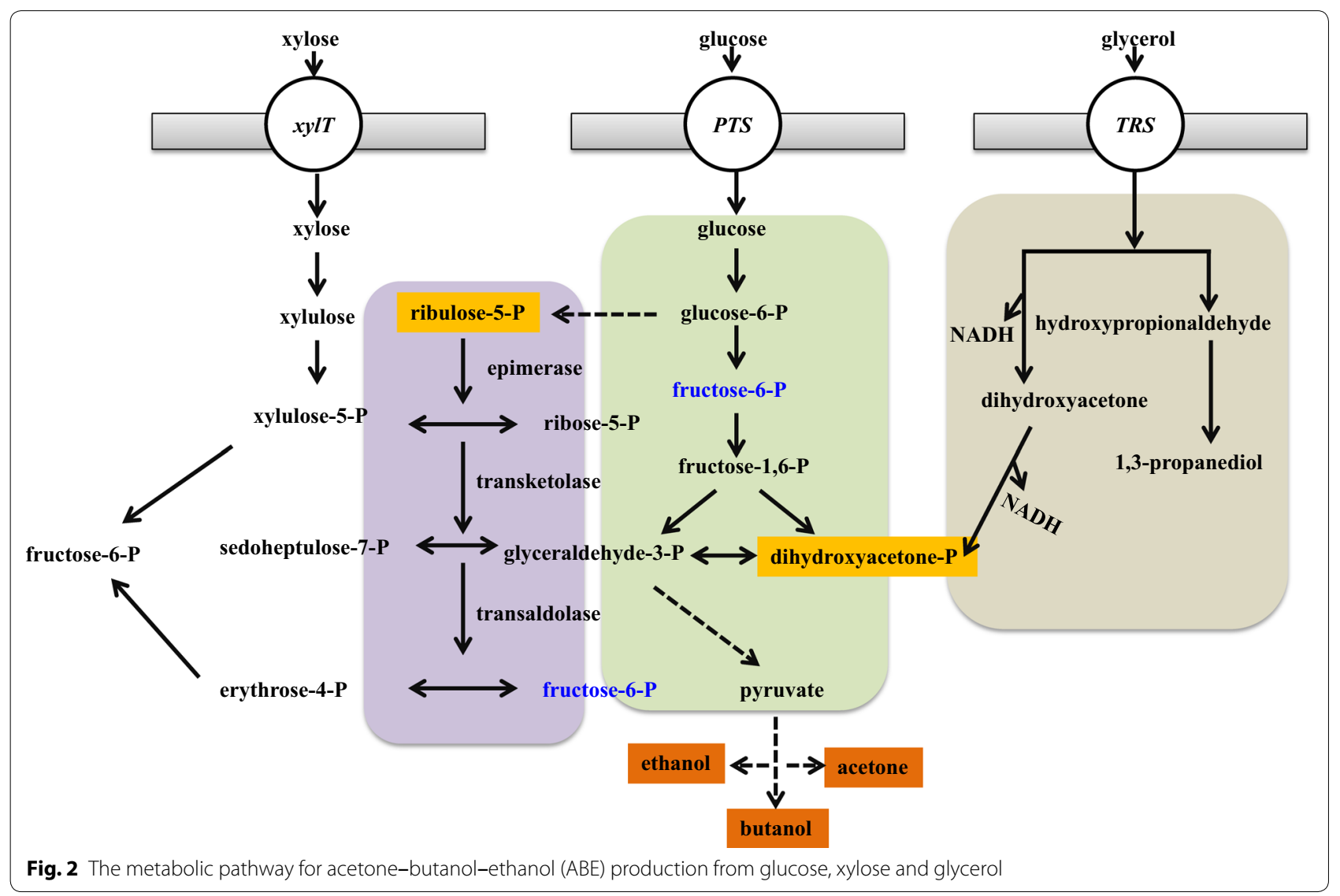


Table 1 Solvent production by different native Clostridium sp. strains

\begin{tabular}{|c|c|c|c|c|}
\hline Strain & Substrate & Fermentation pattern & Solvents (g/L) & References \\
\hline Clostridium sp. strain $\mathrm{BOH} 3$ & Xylose & Acetone-butanol-ethanol (ABE) & $5.32 \mathrm{~g} / \mathrm{L}$ acetone, $14.94 \mathrm{~g} / \mathrm{L}$ butanol, $1.25 \mathrm{~g} / \mathrm{L}$ ethanol & [34] \\
\hline C. tetanomorphum strain DSM665 & Glucose & Butanol-ethanol (BE) & $9.81 \mathrm{~g} / \mathrm{L}$ butanol, $1.01 \mathrm{~g} / \mathrm{L}$ ethanol & {$[20]$} \\
\hline C. pasteurianum DSM 525 & Glycerol & Butanol-propanediol & $7.13 \mathrm{~g} / \mathrm{L}$ butanol, $6.79 \mathrm{~g} / \mathrm{L}$ 1,3-propanediol & [44] \\
\hline Clostridium sp. BT10-6 & Glucose & Isopropanol & $5.26 \mathrm{~g} / \mathrm{L}$ isopropanol & [23] \\
\hline Clostridium sp. strain NJP7 & Glucose & Isopropanol-butanol (IB) & $12.21 \mathrm{~g} / \mathrm{L}$ butanol, $1.92 \mathrm{~g} / \mathrm{L}$ ethanol & [24] \\
\hline C. pasteurianum strain GL11 & Glycerol & Butanol-ethanol (BE) & $14.7 \mathrm{~g} / \mathrm{L}$ butanol & {$[46]$} \\
\hline
\end{tabular}

NADH generated in the cellular glycerol catabolism. $C$. pasteurianum, which was first described in 1983 could indigenously metabolize glycerol for butanol synthesis, representing the best studied organism able to naturally produce butanol with glycerol as the sole carbon and energy source. The main product of this fermentation type was butanol; however, 1,3-propanediol and ethanol were also produced [41, 42] (Fig. 2). It should be mentioned that when C. pasteurianum is fermented with glucose, it produces mostly VFAs rather than solvents, and glycerol has been proved as the best substrate for butanol production by $C$. pasteurianum. Butanol formation alone by $C$. pasteurianum has been shown to be energetically preferred and its pathway has a neutral redox balance. However, along with the formation of biomass, it is suggested that 1,3-propanediol has to be produced to balance reducing equivalents [43].

Currently, C. pasteurianum DSM 525 was the most commonly used one for butanol production from glycerol. $7.13 \mathrm{~g} / \mathrm{L}$ of butanol and $6.79 \mathrm{~g} / \mathrm{L}$ of 1,3-propanediol could be produced from $46.38 \mathrm{~g} / \mathrm{L}$ of glycerol by C. pasteurianum DSM 525 [44]. After fermentation process optimization, the final butanol and 1,3-propanediol titers could be further improved to $13.92 \mathrm{~g} / \mathrm{L}$ and $5.34 \mathrm{~g} / \mathrm{L}$, respectively [45]. However, the high ratio of 1,3-propanediol to butanol leads to low butanol yield and also causes the increased cost associated with downstream product recovery. Recently, solventogenic and glycerol utilizing C. pasteurianum strain GL11 was successfully isolated, which could produce $14.72 \mathrm{~g} / \mathrm{L}$ of butanol from $34 \mathrm{~g} / \mathrm{L}$ of glycerol without formation of by-products including acetone and 1,3-propanediol (1,3-PDO). The elimination of byproducts gave a high butanol yield of $0.43 \mathrm{~g} / \mathrm{g}$ from glycerol. With further in situ extraction using biodiesel, the butanol production was finally improved to $28.83 \mathrm{~g} / \mathrm{L}$ in the fed batch mode. Further genomic and enzymatic analysis showed that the deficiency of key enzymes involved in acetone and 1,3-PDO pathways within strain GL11 led to the elimination of these by-products, which also may greatly simplify the downstream separation. Both the elimination of acetone and 1,3-PDO and high butanol tolerance contributed to its high butanol production yield from glycerol, surpassing the theoretical yield from glucose [46]. Thus, strain GL11 could be a very promising chassis for further improvement of butanol production and shows great potential for large scaling production of butanol from waste glycerol (Table 1).

\section{Butanol producers capable of utilizing gaseous substrates} Syngas, a mixture of hydrogen $\left(\mathrm{H}_{2}\right)$, carbon monoxide (CO) and carbon dioxide $\left(\mathrm{CO}_{2}\right)$ can be used as carbon and energy sources by several solventogenic microorganisms. Butanol production from syngas is only scarcely found in some autotrophic acetogens. During these, solventogenic C. carboxidivorans has been reported to possess the ability to convert syngas to butanol [14, 47]. However, it should be noticed that butanol fermentation pattern did not follow the traditional ABE one, as acetone was normally not found in these species, while other solvents like hexanol could be formed. As far as known, the $\mathrm{C} 4$ formation pathway is identical to that in C. acetobutylicum. A thiolase (ThlA) combines two molecules of acetyl-CoA into acetoacetyl-CoA, which in turn is reduced to 3-hydroxybutyryl-CoA by 3-hydroxybutyryl-CoA dehydrogenase ( $\mathrm{Hbd})$. Then, crotonase (Crt) dehydrates 3-hydroxybutyryl-CoA to crotonyl-CoA, which is finally reduced to butyryl-CoA by electronbifurcating butyryl-CoA dehydrogenase (Bcd) complex [48]. Butyryl-CoA can then either be converted into butyrate (by phosphotransbutyrylase and butyrate kinase or by acetate:coenzyme A transferase and acetate kinase, respectively) or to butanol (by butyraldehyde and butanol dehydrogenases). Coenzyme specificity has been determined for only few butyraldehyde and butanol dehydrogenases. The bifunctional enzyme adhE2 from $C$. acetobutylicum uses NADH for both reactions and has been used in construction of autotrophic recombinants [49].

C. carboxidivorans turned out to be the species that scientific attention focused on recently, which is also able to form the C6 compound of hexanol. It was found that low partial pressure of $\mathrm{CO}$ in the headspace, coupled with restricted mass transfer for $\mathrm{CO}$ and $\mathrm{H}_{2}$, was required for the successful fermentation of $C$. carboxidivorans 
strain P7. In the absence of substrate inhibition (particularly from $\mathrm{CO}$ ), growth limitation increased alcohols production, especially butanol and hexanol. $1.00 \mathrm{~g} / \mathrm{L}$ of butanol, $1.00 \mathrm{~g} / \mathrm{L}$ of hexanol and $3.00 \mathrm{~g} / \mathrm{L}$ of ethanol were achieved in bottle fermentations. Different from sugar-based medium, operating conditions significantly affect the metabolic fermentation profiles and butanol accumulation of C. carb.oxidivorans. In batch fermentation without $\mathrm{pH}$ regulation, acetic acid, butyric acid and ethanol were detected while only negligible butanol production was observed after complete substrate exhaustion. Maximum ethanol and butanol concentrations in the bioreactors were obtained at $\mathrm{pH} 5.75$, reaching values of 5.55 and $2.66 \mathrm{~g} / \mathrm{L}$, respectively, demonstrating that low $\mathrm{pH}$ was more favorable to solventogenesis in this process, although it negatively affects biomass growth, which also plays a role in the final alcohol titer [47]. Currently, the highest butanol concentration obtained with the natural butanol producer $C$. carboxidivorans is still much lower than that obtained with mutants of $C$. acetobutylicum [14]. Thus, it is tempting to try a metabolic engineering approach to enhance butanol production capacity.

\section{Novel bacterial genus for butanol production}

Extensive works regarding genetical construction of some model microorganisms, such as Escherichia coli and $S$. cerevisiae, have been carried out for the achievement of biobutanol production [50-53]. Not only limited to expanding butanol producers through metabolic engineering, some other bacterial genus with the capability of butanol production was also isolated and characterized. Recently, our group has isolated and characterized a new thermophilic Thermoanaerobacterium sp. M5, which could directly produce butanol from hemicellulose through CBP at $55^{\circ} \mathrm{C}$, which features hydrolytic enzymes production, enzymatic hydrolysis and butanol fermentation in one step. Moreover, strain M5 possesses a unique $\mathrm{BE}$ pathway with the elimination of acetone [54]. Generally, thermophilic conditions could avoid microbial contamination, decrease the cooling system cost and further facilitate the downstream product recovery. Currently, most wild type thermophilic strains, such as $C$. thermocellum, T. saccharolyticum, Geobacillus thermoglucosidasius et al. have been reported to produce ethanol alone [17]. This newly isolated and characterized butanologenic strain will broaden our knowledge and add to the pool of known butanol generating microbes.

Through the optimization of fermentation process, strain M5 could produce $1.17 \mathrm{~g} / \mathrm{L}$ of butanol from xylan to CBP, in which xylanase production and butanol fermentation were both completed by strain M5. Genomic and proteomic analysis showed that the capabilities of efficient hemicellulose degradation and butanol synthesis were attributed to the efficient expression of hemicellulose degradation systems, mainly xylanase and $\beta$-xylosidase, and the bifunctional alcohol/aldehyde dehydrogenase (AdhE). Owning to its efficient hemicellulose degradation systems, the co-cultivation system consisting of Thermoanaerobacterium sp. M5 and solventogenic C. acetobutylicum NJ4 could further improve the final butanol titer to $8.34 \mathrm{~g} / \mathrm{L}$, representing the highest butanol production from xylan to CBP. It should be noticed that high amount of butyric acid was formed compared to solvents; hence, further genetic overexpression of AdhE may help to improve the final butanol titer. As a newly identified thermophilic and butanologenic strain, more detailed analysis of enzymes responsible for butanol formation is still needed, and more thermophilic enzymes could be identified and adopted as genetic tools for other strains' modification [55].

\section{Conclusions and future perspectives}

Large scaling biobutanol production through ABE fermentation process remains a great challenge, primarily due to the low butanol titer caused by the toxicity of butanol to cells and low yield caused by the formation of by products, mainly acetone [56]. Over the past few years, strategies for achieving high butanol production with low acetone production by solventogenic Clostridium sp. have been well developed. Currently, acetone formation could be completely suppressed or converted into more valuable product, such as isopropanol through metabolic engineering or newly isolated strains. In parallel, the rapid development of genetic tools for molecular characterization of complex phenotypes has led to numerous new insights into butanol tolerance, and various solventogenic Clostridium sp. have been genetically engineered to improve the butanol tolerance and final butanol titer. However, due to the complex of metabolic regulation of proteins or enzymes involved in the butanol tolerance, there is still lack of sufficient tools to significantly improve the final butanol titer. It has been proved that the most efficient method is still through the traditional chemical mutagenesis; however, butanol production still maintained at low levels (below $20 \mathrm{~g} / \mathrm{L}$ ), which can not compete with ethanol production. Integration of novel strain isolation and metabolic evolution may pave a way for selection of more promising butanol producers [57-61].

\section{Authors' contributions}

FXX conceived, designed and drafted the paper. JZ and WY wrote the part of 'background'. HW and WLD wrote the part of 'strains with untraditional patterns.' JFM and WMZ wrote the part of 'strains with different substrate'. FXX and MJ wrote the part of 'novel genus' and critically revised the manuscript. All authors read and approved the final manuscript. 


\begin{abstract}
Author details
${ }^{1}$ State Key Laboratory of Materials-Oriented Chemical Engineering, College of Biotechnology and Pharmaceutical Engineering, Nanjing Tech University, Puzhu South Road 30\#, Nanjing 211816, People's Republic of China. ${ }^{2}$ Jiangsu National Synergetic Innovation Center for Advanced Materials (SICAM), Nanjing Tech University, Nanjing 211816, People's Republic of China.
\end{abstract}

\section{Acknowledgements}

Not applicable.

\section{Competing interests}

The authors declare that they have no competing interests.

\section{Availability of data and materials}

Not applicable.

\section{Consent for publication}

All authors consent the manuscript for publication in Biotechnology for Biofuels.

\section{Ethics approval and consent to participate}

Not applicable.

\section{Funding}

This work was supported by the Jiangsu Province Natural Science Foundation for Youths (BK20170993, BK20170997), the Jiangsu Synergetic Innovation Center for Advanced Bio-Manufacture (XTE1840), the Project of State Key Laboratory of Materials-Oriented Chemical Engineering (KL16-08), the Key Science and Technology Project of Jiangsu Province (BE2016389), and the National Natural Science Foundation of China (No. 21706125, No. 21727818, No. 21706124, No. 31700092).

\section{Publisher's Note}

Springer Nature remains neutral with regard to jurisdictional claims in published maps and institutional affiliations.

\section{Received: 11 June 2018 Accepted: 6 September 2018} Published online: 18 September 2018

\section{References}

1. Green EM. Fermentative production of butanol-the industrial perspective. Curr Opin Biotechnol. 2011;22:337-43.

2. Xue C, Zhao XQ, Liu CG, Chen LJ, Bai FW. Prospective and development of butanol as an advanced biofuel. Biotechnol Adv. 2013;31:1575-84.

3. Lee SY, Park JH, Jang SH, Nielsen LK, Kim J, Jung KS. Fermentative butanol production by Clostridia. Biotechnol Bioeng. 2008;101:209-28.

4. Schiel-Bengelsdorf B, Montoya J, Linder S, Dürre P. Butanol fermentation. Environ Technol. 2013;34:1691-710.

5. Sauer M. Industrial production of acetone and butanol by fermentation-100 years later. FEMS Microbiol Lett. 2016;363:fnw134.

6. Gu Y, Jiang Y, Wu H, Liu X, Li Z, Li J, Xiao H, Shen Z, Dong H, Yang Y, Li $Y$, Jiang W, Yang S. Economical challenges to microbial producers of butanol: feedstock, butanol ratio and titer. Biotechnol J. 2011;11:1348-67.

7. Atsumi S, Hanai T, Liao JC. Non-fermentative pathways for synthesis of branched-chain higher alcohols as biofuels. Nature. 2008:451:86-9.

8. Sun C, Zhang S, Xin F, Shanmugam S, Wu YR. Genomic comparison of Clostridium species with the potential of utilizing red algal biomass for biobutanol production. Biotechnol Biofuels. 2018;11:42.

9. Ryosuke $\mathrm{Y}$, Tomohisa H, Akihiko K. Endowing non-cellulolytic microorganisms with cellulolytic activity aiming for consolidated bioprocessing Biotechnol Adv. 2013;31:754-63.

10. Liao Z, Zhang Y, Luo S, Suo Y, Zhang S, Wang J. Improving cellular robustness and butanol titers of Clostridium acetobutylicum ATCC824 by introducing heat shock proteins from an extremophilic bacterium. J Biotechnol. 2017;252:1-10.

11. Youn SH, Lee KM, Kim KY, Lee SM, Woo HM, Um Y. Effective isopropanolbutanol (IB) fermentation with high butanol content using a newly isolated Clostridium sp. A1424. Biotechnol Biofuels. 2016;9:230.
12. Lee J, Jang YS, Choi SJ, Im JA, Song H, Cho JH, Seung Y, Papoutsakis ET, Bennett GN, Lee SY. Metabolic engineering of Clostridium acetobutylicum ATCC 824 for isopropanol-butanol-ethanol fermentation. Appl Environ Microbiol. 2011;78:1416-23.

13. Jang YS, Malaviya A, Lee J, Im JA, Lee SY, Lee J, Eom MH, Cho JH, Seung Y. Metabolic engineering of Clostridium acetobutylicum for the enhanced production of isopropanol-butanol-ethanol fuel mixture. Biotechnol Prog. 2013;29:1083-8.

14. Dürre P. Biobutanol: an attractive biofuel. Biotechnol J. 2007:2:1525-34.

15. Shaheen R, Shirley M, Jones DT. Comparative fermentation studies of industrial strains belonging to four species of solvent-producing clostridia. J Mol Microbiol Biotechnol. 2000;2:115-24.

16. Shanmugam S, Sun C, Zeng X, Wu YR. High-efficient production of biobutanol by a novel Clostridium sp. strain WST with uncontrolled pH strategy. Bioresour Technol. 2018;256:543-7.

17. Jiang YJ, Xin FX, Lu JS, Dong WL, Zhang WM, Zhang $M$, Wu H, Ma JF, Jiang $M$. State of the art review of biofuels production from lignocellulose by thermophilic bacteria. Bioresour Technol. 2017;245(Pt B):1498-506.

18. Dusséaux S, Croux C, Soucaille P, Meynial-Salles I. Metabolic engineering of Clostridium acetobutylicum ATCC 824 for the high-yield production of a biofuel composed of an isopropanol/butanol/ethanol mixture. Metab Eng. 2013;18:1-8

19. Jiang $Y, X u C$, Dong F, Yang $Y$, Jiang W, Yang S. Disruption of the acetoacetate decarboxylase gene in solvent-producing Clostridium acetobutylicum increases the butanol ratio. Metab Eng. 2009;11:284-91.

20. Gone F, Bao G, Zhao C, Zhang Y, Li Y, Dong H. Fermentation and genomic analysis of acetone-uncoupled butanol production by Clostridium tetanomorphum. Appl Microbiol Biotechnol. 2016;100:1523-9.

21. Dai Z, Dong H, Zhu Y, Zhang Y, Li Y, Ma Y. Introducing a single secondary alcohol dehydrogenase into butanol-tolerant Clostridium acetobutylicum Rh8 switches ABE fermentation to high level IBE fermentation. Biotechnol Biofuels. 2012;5:44

22. Survase SA, Jurgens G, Heiningen AV, Granstrom T. Continuous production of isopropanol and butanol using Clostridium beijerinckii DSM 6423. Appl Microbiol Biotechnol. 2011;91:1305-13.

23. Ng ZR, Takahashi K, Liu Z. Isolation, characterization and evaluation of hyper 2-propanol producing bacteria from Singapore environment. World J Microbiol Biotechnol. 2013:29:1059-65.

24. Xin F, Chen T, Jiang Y, Dong W, Zhang W, Zhang M, Wu H, Ma J, Jiang M. Strategies for improved isopropanol-butanol production by a Clostridium strain from glucose and hemicellulose through consolidated bioprocessing. Biotechnol Biofuels. 2017;10:118.

25. Wang T, Chen X, Han J, Ma S, Wang J, Li X, Zhang H, Liu Z, Yang Y. Effects of the cofactor binding sites on the activities of secondary alcohol dehydrogenase (SADH). Int J Biol Macromol. 2016;88:385-91.

26. Cheng HH, Whang LM, Chan KC, Chung MC, Wu SH, Liu CP. Biological butanol production from microalgae-based biodiesel residues by Clostridium acetobutylicum. Bioresour Technol. 2015;184:379-85.

27. Cai D, Dong Z, Wang Y, Chen C, Li P, Qin P, Wang Z, Tan T. Co-generation of microbial lipid and bio-butanol from corn cob bagasse in an environmentally friendly biorefinery process. Bioresour Technol. 2016;216:345-51.

28. Kwak S, Jin YS. Production of fuels and chemicals from xylose by engineered Saccharomyces cerevisiae: a review and perspective. Microb Cell Fact. 2017;16:82.

29. Grimmler C, Held C, Liebl W, Ehrenreich A. Transcriptional analysis of catabolite repression in Clostridium acetobutylicum growing on mixtures of D-glucose and D-xylose. J Biotechnol. 2010;150:315-23.

30. Gu Y, Li J, Zhang L, Chen J, Niu LX, Yang YL, Yang S, Jiang HW. Improvement of D-xylose utilization in Clostridium acetobutylicum via expression of the talA gene encoding transaldolase from Escherichia coli. J Biotechnol. 2009;143:284-7.

31. Xiao H, Li Z, Jiang Y, Yang Y, Jiang W, Gu Y, Yang S. Metabolic engineering of D-xylose pathway in Clostridium beijerinckii to optimize solvent production from D-xylose mother liquid. Metab Eng. 2012;14:569-78.

32. Xiao H, Gu Y, Ning Y, Yang Y, Mitchell WJ, Jiang W, Yang S. Confirmation and elimination of D-xylose metabolism bottlenecks in D-glucose phosphoenolpyruvate-dependent phosphotransferase system-deficient Clostridium acetobutylicum for simultaneous utilization of D-glucose, D-xylose, and arabinose. App Env Microbiol. 2011;77:7886-95.

33. Vinuselvi P, Minkyung K, Sungkuk L, Cheolmin G. Rewiring carbon catabolite repression for microbial cell factory. BMB Rep. 2012;45:59-70. 
34. Xin F, Wu YR, He J. Simultaneous fermentation of glucose and xylose to butanol by Clostridium sp. strain BOH3. Appl Environ Microbiol. 2014;80:4771-8

35. Volesky B, Szczesny T. Bacterial conversion of pentose sugars to acetone and butanol. Adv Biochem Eng Biotechnol. 1983;27:101-17.

36. Zeikus JG. Chemical and fuel production by anaerobic bacteria. Annu Rev Microbiol. 1980;34:423-64.

37. Gottschalk G. Bacterial metabolism. 2nd ed. New York: Springer; 1986. p. 1-380.

38. Cynkin MA, Delwiche EA. Metabolism of pentoses by Clostridia. I. Enzymes of ribose dissimilation in extracts of Clostridium perfringens. J Bacteriol. 1958;75:331-4.

39. Cynkin MA, Gibbs M. Metabolism of pentose by clostridia. II. The fermentation of C14-labeled pentoses by Clostridium perfringens, Clostridium beijerinckii, and Clostridium butylicum. J Bacteriol. 1958;75:335-8.

40. Dobson R, Gray V, Rumbold K. Microbial utilization of crude glycerol for the production of value-added products. J Ind Microbiol Biotechnol. 2012;39:217-26.

41. Malaviya A, Jiang YS, Lee SY. Continuous butanol production with reduced byproducts formation from glycerol by a hyper producing mutant of Clostridium pasteurianum. Appl Microbiol Biotechnol. 2012;93:1485-94

42. Wischral D, Zhang J, Cheng C, Lin M, De Souza LM, Pessoa FL, Pereira NJ, Yang ST. Production of 1,3-propanediol by Clostridium beijerinckii DSM

791 from crude glycerol and corn steep liquor: process optimization and metabolic engineering. Bioresour Technol. 2016;212:100-10.

43. Sandoval NR, Venkataramanan KP, Groth TS, Papoutsakis ET. Wholegenome sequence of an evolved Clostridium pasteurianum strain reveals Spo0A deficiency responsible for increased butanol production and superior growth. Biotechnol Biofuels. 2015;8:227-45.

44. Gallardo R, Alves M, Rodrigues LR. Influence of nutritional and operational parameters on the production of butanol or 1,3-propanediol from glycerol by a mutant Clostridium pasteurianum. N Biotechnol. 2017;34:59-67.

45. Sabra W, Groeger C, Sharma PN, Zeng AP. Improved $n$-butanol production by a non-acetone producing Clostridium pasteurianum DSMZ 525 in mixed substrate fermentation. Appl Microbiol Biotechnol. 2014;98:4267-76.

46. Xin F, Wang C, Dong W, Zhang W, Wu H, Ma J, Jiang M. Comprehensive investigations of biobutanol production by a non-acetone and 1,3-propanediol generating Clostridium strain from glycerol and polysaccharides. Biotechnol Biofuels. 2016;9:220.

47. Phillips JR, Atiyeh HK, Tanner RS, Torre JR, Saxena J, Wilkins MR, Huhnke RL. Butanol and hexanol production in Clostridium carboxidivorans syngas fermentation: medium development and culture techniques. Bioresour Technol. 2015;190:114-21.
48. Li N, Yang J, Chai C, Yang S, Jiang W, Gu Y. Complete genome sequence of Clostridium carboxidivorans P7T, a syngas-fermenting bacterium capable of producing long-chain alcohols. J Biotechnol. 2015;211:44-5.

49. Bruant G, Lévesque MJ, Peter C, Guiot SR, Masson L. Genomic analysis of carbon monoxide utilization and butanol production by Clostridium carboxidivorans strain P7. PLoS ONE. 2010;5:e13033.

50. Dong H, Zhao C, Zhang T, Zhu H, Lin Z, Tao W, Zhang Y, Li Y. A systematically chromosomally engineered Escherichia coli efficiently produces butanol. Metab Eng. 2017;44:284-92.

51. Saini M, Lin LJ, Chiang CJ, Chao YP. Synthetic consortium of Escherichia coli for $n$-butanol production by fermentation of the glucose-xylose mixture. J Agric Food Chem. 2017;65:10040-7.

52. Turner TL, Kim H, Kong II, Liu JJ, Zhang GC, Jin YS. Engineering and evolution of Saccharomyces cerevisiae to produce biofuels and chemicals. Adv Biochem Eng Biotechnol. 2018;162:175-215.

53. Shi S, Si T, Liu Z, Zhang H, Ang EL, Zhao H. Metabolic engineering of a synergistic pathway for $n$-butanol production in Saccharomyces cerevisiae. Sci Rep. 2016:6:25675.

54. Jiang Y, Guo D, Lu J, Dürre P, Dong W, Yan W, Zhang W, Ma J, Jiang M, Xin F. Consolidated bioprocessing of butanol production from xylan by a thermophilic and butanologenic Thermoanaerobacterium sp. M5. Biotechnol Biofuels. 2018;11:89.

55. Haki GD, Rakshit SK. Developments in industrially important thermostable enzymes: a review. Bioresour Technol. 2003;89:17-34.

56. Zhang YH. Production of biofuels and biochemical by in vitro synthetic biosystems: opportunities and challenges. Biotechnol Adv. 2015:33:1467-83.

57. Bormann S, Baer ZC, Sreekumar S, Kuchenreuther JM, Dean TF, Blanch HW, Clark DS. Engineering Clostridium acetobutylicum for production of kerosene and diesel blendstock precursors. Metab Eng. 2014;25:124-30

58. Sreekumar S, Baer ZC, Pazhamalai A, Gunbas G, Grippo A, Blanch HW, Clark DS, Toste FD. Production of an acetone-butanol-ethanol mixture from Clostridium acetobutylicum and its conversion to high-value biofuels. Nat Protoc. 2015;10:528-37.

59. Van den Berg C, Heeres AS, van der Wielen LA, Straathof AJ. Simultaneous Clostridial fermentation, lipase-catalyzed esterification, and ester extraction to enrich diesel with butyl butyrate. Biotechnol Bioeng. 2013:110:137-42.

60. Xin F, Basu A, Yang KL, He J. Strategies for production of butanol and butyl-butyrate through lipase-catalyzed esterification. Bioresour Technol. 2016;202:214-9.

61. Xin F, Dong W, Jiang Y, Ma J, Zhang W, Wu H, Zhang M, Jiang M. Recent advances on conversion and co-production of acetone-butanol-ethanol into high value-added bioproducts. Crit Rev Biotechnol. 2017;14:1-12.
Ready to submit your research? Choose BMC and benefit from:

- fast, convenient online submission

- thorough peer review by experienced researchers in your field

- rapid publication on acceptance

- support for research data, including large and complex data types

- gold Open Access which fosters wider collaboration and increased citations

- maximum visibility for your research: over 100M website views per year

At $\mathrm{BMC}$, research is always in progress.

Learn more biomedcentral.com/submissions 